\title{
Amniocentesis in the West Midlands: report on 1000 births
}

\author{
TESSA WEBB,* J H EDWARDS,* A H CAMERON, $\dagger$ \\ J MARGARET CRAWLEY, MAJ HULTEN, $\$$ D I RUSHTON, \\ AND R A THOMPSONT \\ From the *Departments of Clinical Genetics, $\ddagger$ Biochemistry, and $\|$ Pathology, Birmingham Maternity \\ Hospital; $\dagger$ Department of Pathology, Birmingham Children's Hospital; and the §Regional \\ Cytogenetics Laboratory, and 9 Department of Immunology, East Birmingham Hospital, Birmingham
}

SUMMARY Two laboratories in the West Midlands have monitored 1000 'at risk' pregnancies. Of these $57 \%$ were referred for chromosomal indications and $43 \%$ for possible neural tube defects. The largest at risk groups (both $37 \%$ ) were those mothers who had already had a pregnancy resulting in a baby with a neural tube defect ( $21 \%$ spina bifida and $16 \%$ anencephaly), and those who were referred because of the increased risk of Down's syndrome in pregnancies where the mother was over 35 years old. Six percent had already borne a child with Down's syndrome.

An estimate of the AFP level in the amniotic fluid was achieved in $985(98.5 \%)$ of the pregnancies. Of these, 967 mothers could be reassured that the baby did not have an open neural tube defect and 18 abnormal fetuses were terminated or died spontaneously.

Chromosome studies were completed in $846(85 \%)$ of the pregnancies with the consequence that 19 were terminated. Of these, 15 had an abnormal karyotype, including nine with Down's syndrome. Four male fetuses were terminated because of a high chance of carrying $\mathrm{X}$ linked disease.

The 1000 pregnancies monitored required 1080 amniocenteses. Cases were excluded from this study if the amniocentesis took place after the 20th week of gestation and if follow-up data concerning the outcome had not been received. This follow-up data was obtained through a questionnaire, but only ten cases were lost to the study at this point, mainly because the subject had moved away from the area before the birth of her child.

This report describes the amniocentesis service offered by the West Midlands Regional Health Authority. The area serves a population of $5.5 \times 10^{6}$ and there are about 65000 births a year. The first 200 pregnancies monitored were part of a pilot study carried out in the Department of Cancer Studies of the University of Birmingham between 1972 and 1975 and are not included in this report.

Received for publication 10 September 1979
In the Autumn of 1975 the diagnostic amniocentesis service in the West Midlands was established in two areas, one served by the laboratories at Birmingham Maternity Hospital (BMH) and the other by those at East Birmingham Hospital $(\mathrm{EBH})$. Since then 1000 pregnancies of known outcome have been monitored. The distribution of these between the two laboratories is shown in table 1 .

TABLE 1 Total number of pregnancies monitored

\begin{tabular}{|c|c|c|c|c|c|c|}
\hline Laboratory & $\begin{array}{l}\text { Total No of } \\
\text { amniocenteses } \\
\text { performed }\end{array}$ & $\begin{array}{l}\text { Total No of } \\
\text { amniocentesis } \\
\text { failures }\end{array}$ & $\begin{array}{l}\text { Total No of } \\
\text { births }\end{array}$ & Males & Females & $\begin{array}{l}\text { No of twin } \\
\text { births }\end{array}$ \\
\hline $\begin{array}{l}\text { BMH } \\
\text { EBH }\end{array}$ & $\begin{array}{l}531 \\
549\end{array}$ & $\begin{array}{r}46 \\
6\end{array}$ & $\begin{array}{l}474 \\
526\end{array}$ & $\begin{array}{l}216 \\
475\end{array}$ & $\begin{array}{l}196 \\
434\end{array}$ & $\begin{array}{l}3 \\
4\end{array}$ \\
\hline $\begin{array}{l}\text { BMH } \\
\text { EBH }\end{array}$ & \multicolumn{2}{|c|}{$\begin{array}{l}\text { No of spontaneous abortions } \\
10 \\
17\end{array}$} & \multicolumn{2}{|c|}{$\begin{array}{l}\text { No of stillbirths or NND } \\
9+(1)^{*} \\
7\end{array}$} & \multicolumn{2}{|c|}{$\begin{array}{l}\text { No of terminations } \\
13+(3) \dagger \\
18+(4) \dagger\end{array}$} \\
\hline
\end{tabular}

*Meckel's syndrome with 2 failed amniocenteses.

†Includes terminations of male fetuses at risk for $\mathbf{X}$ linked disease. 


\section{Indications for amniocentesis}

The distribution of all the cases by indication is given in table 2. An expanded version giving miscellaneous indications in more detail is given in table 3 .

It can be seen that, unlike some other studies, ${ }^{12}$ the numbers presented for chromosomal and neural indications are approximately equal.

\section{DOUBLE INDICATIONS}

In all, 64 pregnancies had double indications. In each case the primary indication used for this study was the one defined by the consultant obstetrician (table 4).

TABLE 2 Distribution of cases by indication

\begin{tabular}{lr}
\hline Chromosomal indications & $N o$ \\
\hline Maternal age 40+ & 243 \\
Maternal age 35-39 & 125 \\
Previous child with trisomy 21 & 63 \\
Previous child with other aneuploidies & 8 \\
Previous child with other chromosomal abnormalities & 6 \\
Parental translocation & 7 \\
Family history of trisomy 21 (not previous child) & 49 \\
Previous congenital abnormalities in child & 31 \\
X linked disease & 11 \\
Others & 19 \\
Total & 562 \\
Neural tube defect and related indications & $N o$ \\
\hline Previous child with spina bifida & 199 \\
Previous child with anencephaly & 158 \\
Previous child with exomphalos & 1 \\
Previous child with Finnish nephrotic syndrome & 1 \\
Previous child with hydrocephaly & 22 \\
Family history of NTD (excluding previous child) & 39 \\
Previous children with neural tube defect (two) & 5 \\
Neural tube defect in parent & 9 \\
Other & 4 \\
Total & 438 \\
\hline
\end{tabular}

TABLE 3 Expansion of indications

\begin{tabular}{lc}
\hline & No \\
\hline Chromosomal & \\
Previous child with trisomy 18 & 4 \\
Previous child with trisomy 13 & 1 \\
Previous child with triploidy & 1 \\
Previous child with XYY syndrome & 1 \\
Previous child with Turner's syndrome & 1 \\
Total & 8 \\
Previous intersex child & 1 \\
Drug therapy in parent & 7 \\
Anxiety over age (less than 35 years) & 6 \\
$X$-rays of mother during present pregnancy & 2 \\
Previous spontaneous abortion & 2 \\
Threatened abortion in present pregnancy & 1 \\
Total & 19 \\
Neural tube defect & \\
Unusual ultrasound of present pregnancy & 3 \\
Hydramnios of present pregnancy & 1 \\
Total & 4 \\
$X$ linked disease (mother suspected carrier) & \\
Muscular dystrophy & 5 \\
Imaemophilia & 4 \\
Retinitis pigmentosa & 1 \\
Total & 1 \\
\hline
\end{tabular}

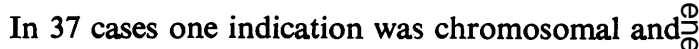
the other for a neural tube defect. Of 27 mothers: over 35 years old who had already had a neural tube $\vec{F}$ defect pregnancy, six aborted or were terminated or had a stillbirth.

\section{HIGH $\alpha$-FETOPROTEIN PREGNANCIES}

In all, 17 abnormal pregnancies were detected; $16 \Omega$ of these were terminated and one case of Meckel's ${ }_{\infty}^{0}$ syndrome died after birth. During this pregnancy amniocentesis failed twice, but the serum AFP level was very high.

The 17 abnormal pregnancies could be divided into nine anencephalics, five with spina bifida, one with Finnish nephrotic syndrome, one macerated fetus, and one with Meckel's syndrome.

Five of these pregnancies had been referred for amniocentesis with chromosomal indications, four ${ }^{-}$ for maternal age, and one who had already borne a child with Down's syndrome.

\section{CHROMOSOMAL ABNORMALITIES}

All chromosomal abnormalities detected are listed $\vec{\theta}$ in table 5 together with the outcome of the pregnancy and the age of the mother. Of the 20 chromosomal anomalies detected $(2.0 \%)$, nine were of

TABLE 4 Pregnancies with double indications

\begin{tabular}{lllr}
\hline Laboratory & $\begin{array}{l}\text { No in which one } \\
\text { indication was } \\
\text { chromosomal and } \\
\text { one NTD }\end{array}$ & $\begin{array}{l}\text { No in which both } \\
\text { indications were } \\
\text { chromosomal }\end{array}$ & Others \\
\hline BMH & 19 & 6 & 10 \\
EBH & 18 & 6 & 5
\end{tabular}

TABLE 5 Chromosomal abnormalities detected

\begin{tabular}{|c|c|c|}
\hline Karyotype & Outcome & Maternal age \\
\hline $\begin{array}{l}\text { 46,XX,22p+ } \\
\text { 47,XY,+G } \\
\text { 47,XY,+G } \\
\text { 47,XX,+G } \\
\text { 47,XY,+G } \\
\text { 46,X,+frag } \\
\text { 47,XY,+D } \\
\text { 46,XX/47,XX, +2 } \\
\text { 47,XY,+G } \\
\text { 47,XX,+E } \\
\text { 46,XX/45,Xo or } 45, \mathbf{X} \\
\text { 46,XX,t(6;7) } \\
\text { 46,XY,t(6;10) } \\
\text { 47,XXY } \\
\text { 48,XXYY } \\
\text { 47,XX,+21 } \\
\text { 47,XY,+21 } \\
\text { 46,XY,t(2;9) } \\
\text { 47,XX,+21 } \\
\text { 47,XX,+21 }\end{array}$ & $\begin{array}{l}\text { TNF } \\
\text { TDO } \\
\text { TDO } \\
\text { TDO } \\
\text { TDO } \\
\text { LTU } \\
\text { TPA } \\
\text { NF } \\
\text { TDO } \\
\text { TED } \\
\text { NF } \\
\text { NF } \\
\text { NM } \\
\text { TKL } \\
\text { TXXYY } \\
\text { TDO } \\
\text { TDO } \\
\text { TM } \\
\text { TDO } \\
\text { TDO }\end{array}$ & $\begin{array}{l}30 \\
33 \\
41 \\
45 \\
45 \\
40 \\
37 \\
40 \\
44 \\
41 \\
25 \\
29 \\
22 \\
44 \\
26 \\
46 \\
38 \\
39 \\
44 \\
45\end{array}$ \\
\hline
\end{tabular}

20 abnormal karyotypes, 15 terminations, 4 normal livebirths, 1 웅 abnormal livebirth.

LTU, live Turner's syndrome; TNF, terminated normal female; $\frac{\rho}{\Phi}$ TDO, terminated trisomy 21; TPA terminated trisomy D; TED terminated trisomy E; TKL, terminated XXY; NF, normal female; NM, normal male; TM, terminated male. 
Down's syndrome $(0.9 \%)$ resulting in each case in a termination. Other terminations included one with trisomy 18 , one with trisomy 13 , one with XXY, one with XXYY, and one de novo balanced translocation. Two balanced translocations and two apparent mosaics came to term with the birth of apparently normal babies. One fluid was diagnosed as $46, X X, 22 p+$; the pregnancy was terminated and the fetus appeared to be a normal female. One pregnancy with a $46, \mathrm{X}$, + fragment came to term (parental decision) with the birth of a female baby with signs consistent with Turner's syndrome.

Two of the balanced translocations and the fetus with the 48,XXYY karyotype were referred for amniocentesis with neural tube defect indications.

Four fetuses with a 46,XY normal male karyotype were aborted because of a high risk of carrying $X$ linked disease.

\section{GESTATION AT AMNIOCENTESIS}

The ideal time for amniocentesis to be performed is at 16 weeks of gestation. Before this gestation, the volume of amniotic fluid may be low and $\alpha$-fetoprotein levels are less discriminatory. Beyond 16 weeks, the time for all the analyses before the possible abortion of an abnormal fetus becomes critical. Table 6 gives the distribution of gestation for the first amniocentesis in the 1000 cases studied. The percentage of culture failures decreases with increasing gestation but the rate of spontaneous fetal loss is independent of gestational age at amniocentesis.

\section{Diagnostic results obtained}

It was not possible to combine the diagnostic results obtained from the two laboratories because, although dry taps were regularly reported by the Birmingham Maternity Hospital laboratory (where $47 \%$ of the specimens were obtained on site), at East Birmingham Hospital (which is some miles from the nearest obstetric unit), no amniocentesis failures were reported, and only six specimens were unsuitable. A check at one particular hospital which keeps very efficient records showed that amniocentesis failures were not always being reported to the laboratory, although they were being recorded.

For this reason, the diagnostic results obtained are not comparable and have been compiled separately. For a true picture of the success rate all dry taps should be reported.

\section{PREGNANCIES WITH NEURAL TUBE DEFECTS}

Those pregnancies which had raised $\alpha$-fetoprotein levels because of a neural tube defect or, in one case, the Finnish nephrotic syndrome, are shown in table 7. One high AFP level has been attributed to intrauterine death and is not included in the table. The level of discrimination achieved is shown in fig 1 and 2 . In these figures, the logarithm of the $\alpha$-fetoprotein value is plotted against the gestation in weeks for each pregnancy.

Table 8 presents a summary of chromosome success rate related to the success of the amniocentesis itself, and shows that blood stained samples

\section{TABLE 7 Raised $\alpha$-fetoprotein pregnancies}

\begin{tabular}{|c|c|c|c|}
\hline $\begin{array}{l}\alpha \text {-fetoprotein level } \\
(\mu g / m l)\end{array}$ & Gestation & Outcome & Maternal age \\
\hline 182 & 16 & TSB & 31 \\
\hline Serum $(955 \mu \mathrm{g} / \mathrm{l})$ & 18 & DMK & 23 \\
\hline 265 & 16 & TAN & 32 \\
\hline 525 & 16 & TAN & 26 \\
\hline 411 & 17 & TFS & 32 \\
\hline 420 & 15 & TAN & 44 \\
\hline 77 & 16 & TSB & 27 \\
\hline 340 & 16 & TAN & 47 \\
\hline 41 & 15 & TSB & 26 \\
\hline 320 & 19 & TAN & 36 \\
\hline 390 & 16 & TAN & 31 \\
\hline 190 & 20 & TAN & 25 \\
\hline 400 & 17 & $\mathbf{T M}^{*}$ & 39 \\
\hline 93 & 16 & TSB & 24 \\
\hline 91 & 15 & TSB & 40 \\
\hline 395 & 17 & TAN & 29 \\
\hline 401 & 15 & TAN & 32 \\
\hline
\end{tabular}

Total $=17$ pregnancies $(1 \cdot 7 \%)$

TSB, terminated spina bifida; TAN, terminated anencephalic; TFS, terminated Finnish syndrome; $\mathrm{TM}^{*}$, terminated macerated fetus; DMK, neonatal death Meckel's syndrome.

TABLE 6 Gestation at first amniocentesis

\begin{tabular}{|c|c|c|c|c|c|c|c|}
\hline \multirow[t]{2}{*}{ Gestation } & \multirow[t]{2}{*}{ No } & \multirow{2}{*}{$\begin{array}{l}\text { No of } \\
\text { spontaneous } \\
\text { abortions }\end{array}$} & \multirow{2}{*}{$\begin{array}{l}\text { No of stillbirths } \\
\text { or NND }\end{array}$} & \multicolumn{4}{|c|}{ No of culture failures } \\
\hline & & & & $B M H$ & $E B H$ & Total & $\%$ \\
\hline $\begin{array}{l}12 \\
13 \\
14 \\
15 \\
16 \\
17 \\
18 \\
19 \\
20 \\
\text { Total }\end{array}$ & $\begin{array}{r}2 \\
8 \\
63 \\
155 \\
403 \\
165 \\
119 \\
54 \\
31 \\
1000\end{array}$ & $\begin{array}{r}-1 \\
2 \\
3 \\
12 \\
5 \\
0 \\
1 \\
1\end{array}$ & $\begin{array}{l}- \\
2 \\
3 \\
7 \\
2 \\
1 \\
1 \\
-\end{array}$ & $\begin{array}{r}-1 \\
8 \\
17 \\
64 \\
15 \\
9 \\
7 \\
3 \\
124\end{array}$ & $\begin{array}{r}- \\
5 \\
15 \\
17 \\
8 \\
5 \\
3 \\
1 \\
54\end{array}$ & $\begin{array}{r}-1 \\
13 \\
32 \\
81 \\
23 \\
14 \\
10 \\
4 \\
178\end{array}$ & $\begin{array}{l}\overline{(12 \cdot 5)} \\
(21) \\
(21) \\
(20) \\
(14) \\
(12) \\
(19) \\
(13)\end{array}$ \\
\hline
\end{tabular}


are, surprisingly, not necessarily more likely to fail. The degree of contamination by red blood cells was a subjective observation by the laboratory staff and need not be comparable between the two laboratories. More chromosome failures occurred in samples which had been obtained without the ai⿱乛龰 of ultrasound.

An increase in the level of spontaneous fetal los was observed in the group where the chromosomes had failed and also when the amniocentesis itse
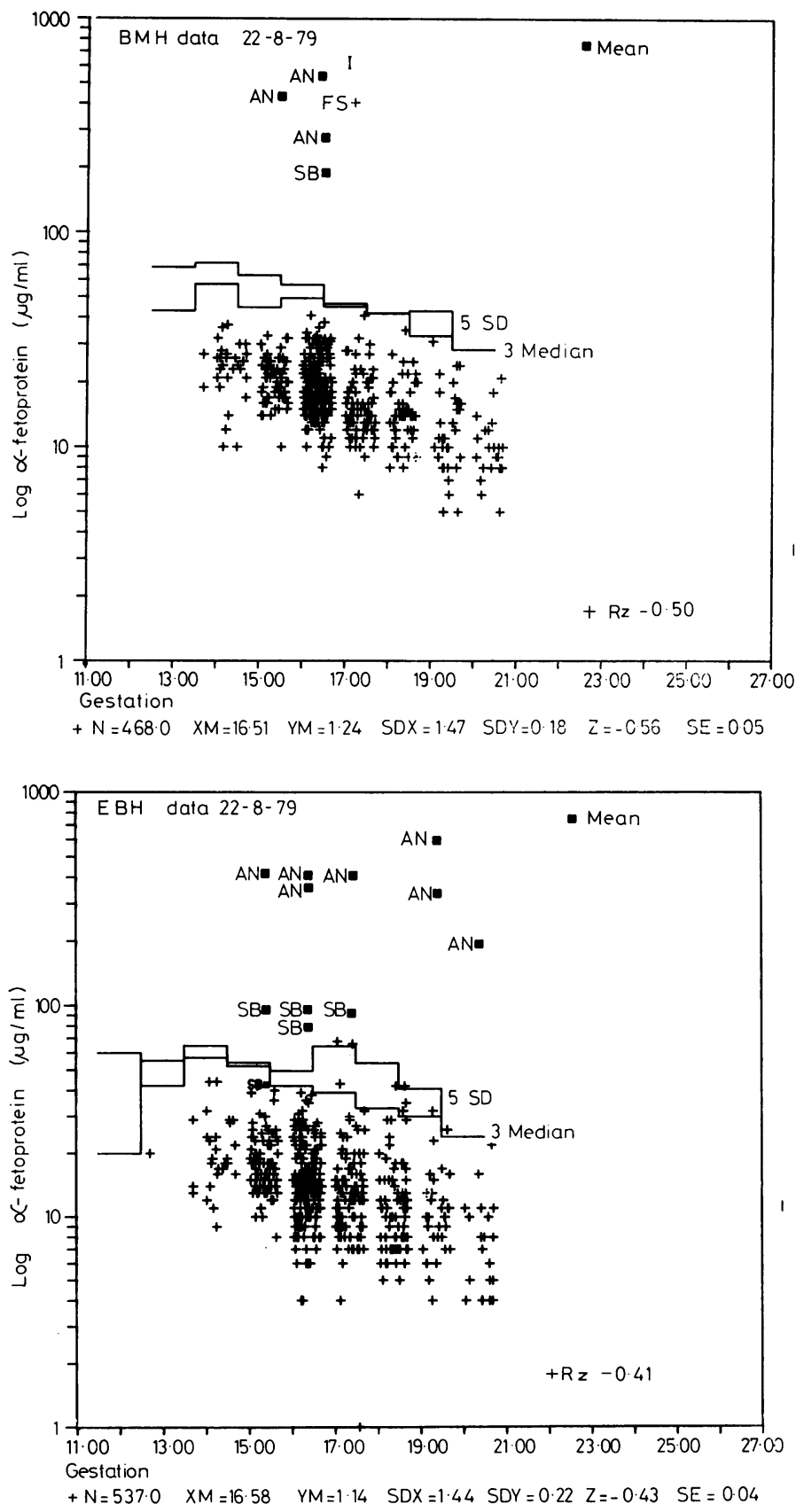

FIG 1 Log $\alpha$-fetoprotein against gestation for pregnancies monitored at in Birmingham Maternity Hospital. Discriminatory lines are at 5 times standard deviation and 3 times median. + , births with normal outcome; $A N$, anencephalic; $S B$, spina bifida; FS, Finnish nephrotic syndrome; I, intrauterine death.

FIG $2 \log \alpha$-fetoprotein against gestation for pregnancies monitored at East Birmingham Hospital.

Discriminatory lines are at 5 times standard deviation and 3 times median. + , births with normal outcome; $A N$, anencephalic; $S B$, spina bifida. 
TABLE 8 Chromosome success rate related to success of amniocentesis

\begin{tabular}{|c|c|c|c|c|c|c|c|}
\hline & \multicolumn{7}{|l|}{ Blood stained samples } \\
\hline & \multicolumn{2}{|c|}{ No of samples with chromosome results } & \multicolumn{3}{|c|}{ No of samples with chromosome failure } & \multicolumn{2}{|c|}{ Amniocentesis failures } \\
\hline \multirow[t]{2}{*}{$\begin{array}{l}\text { BMH } \\
\text { EBH }\end{array}$} & $\begin{array}{l}9(60 \%) \\
26(93 \%) \\
\text { Samples obtained } \\
\text { without ultrasound }\end{array}$ & & $\begin{array}{l}6 \\
2\end{array}$ & & & $\underline{3}$ & \\
\hline & \multicolumn{3}{|c|}{$\begin{array}{ll}\text { Chromosomes normal, } & \begin{array}{l}\text { Chromosomes fail, } \\
\text { outcome normal }\end{array}\end{array}$} & $\begin{array}{l}\text { Chromosomes normal } \\
\text { or abnormal, outcome } \\
\text { abnormal }\end{array}$ & \multicolumn{2}{|c|}{ Amniocentesis failure } & Total \\
\hline \multirow[t]{2}{*}{$\begin{array}{l}\text { BMH } \\
\text { EBH }\end{array}$} & \multicolumn{2}{|c|}{$\begin{array}{lc}21(52.5 \%) & 15(37.5 \%) \\
46(85 \%) & 4(7 \%) \\
\text { Chromosome failures (of first amniocentesis }\end{array}$} & \multicolumn{2}{|c|}{$\begin{array}{c}1(2 \cdot 5 \%) \\
2(4 \%) \\
\text { fluid sample received })\end{array}$} & $\begin{array}{l}3(7 \cdot 5 \% \\
2(4 \%)\end{array}$ & & $\begin{array}{l}40 \\
54\end{array}$ \\
\hline & Total & aneous abnormal ou & utcome & Terminations & & & \\
\hline \multirow[t]{2}{*}{$\begin{array}{l}\text { BMH } \\
\text { EBH }\end{array}$} & \multicolumn{2}{|c|}{$\begin{array}{cr}124 & 7(6 \%) \\
54 & 6(11 \%) \\
\text { Amniocentesis failures }\end{array}$} & & \multirow[t]{3}{*}{$\begin{array}{l}3 \\
1\end{array}$} & & & \\
\hline & Total & \multicolumn{2}{|c|}{ Spontaneous abnormal outcome } & & & & \\
\hline BMH & $5(t$ & \multicolumn{2}{|c|}{$5(+$ one infected placenta) } & & & & \\
\hline
\end{tabular}

TABLE 9 Summary of fetal losses or abnormalities

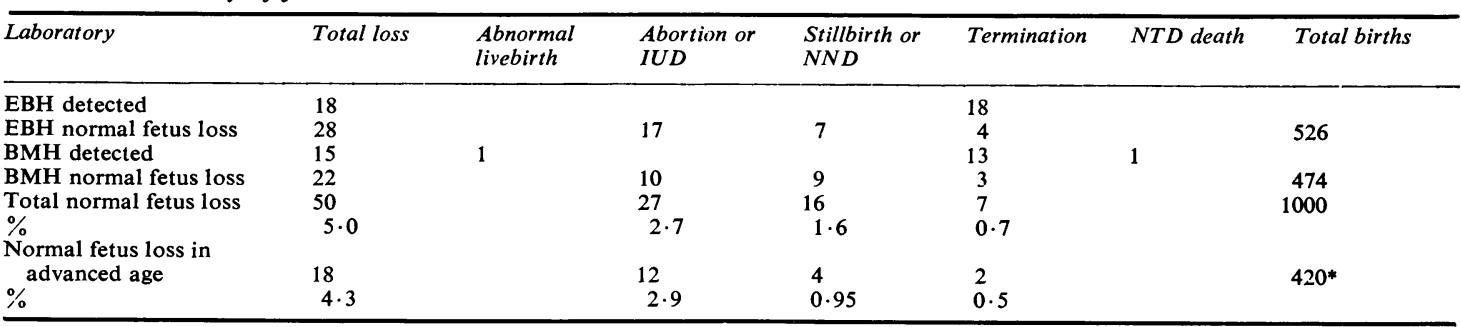

*Includes those with double indications

had failed. When the amniocentesis had to be repeated, there were three cases of spontaneous fetal loss from 57 repeated cases.

\section{Discussion}

High $\alpha$-fetoprotein levels were detected in the amniotic fluid of 16 pregnancies, resulting in each case in the termination of an abnormal fetus. The cut-off point for normality was taken at $3 \times$ median, but the $5 \times$ SD would discriminate similarly (fig 1 , 2). Lines representing both types of cut-off are shown in the figures. One of the laboratories estimated several values lying within the cut-off or 'grey' area including one from a spina bifida fetus which was later terminated. Although several of the fluids were heavily blood stained, the fluids from fetuses with neural tube defects were also blood stained. Some of the patients were referred to Professor S Campbell for spinal scanning. No normal fetuses were later terminated.

The smaller number of amniocentesis failures was reported from the half of the region containing the greater number of small hospitals. In the western half of the region, fluids were received from six centres, three of which sent fewer than 50 samples. By contrast, the laboratories in the eastern half of the region served 14 centres, ten of which sent fewer than 50 fluid samples. The fetal loss rates reflected in these figures were $19 / 474$ in the western region and $24 / 526$ in the other (table 9). In the former, if an amniocentesis 'kit' is broached, then the number is recorded even if the amniocentesis itself fails. In neither centre, however, was the number of needle insertions recorded as has been recommended.

Chromosome studies were attempted on all fluids received despite the pressure on laboratory staff and facilities. One of the reasons for chromosome failure was that insufficient fluid was obtained. The proportion of samples referred for chromosomal indications has risen from $45 \%$ in 1975 to $65 \%$ in 1978 , while the absolute numbers have more than doubled themselves each year. The level of chromosome failure has fallen throughout the three years taken to complete this study. It is felt that laboratories offering this service should not become overstretched too quickly. 
Samples from outlying hospitals reached the laboratories by first class mail but the delay very rarely amounted to more than one day and did not seem to influence the viability of fluid cells. The success rates achieved by the chromosome laboratories can be calculated with respect to either patient numbers or to the number of samples actually received. The BMH laboratory had a $75 \%$ overall success rate with respect to the numbers of patients, while a chromosome result was obtained on $74 \%$ of the samples received. At EBH a successful chromosome culture ensued from $90 \%$ of the samples received, while the success rate per patient reached $93 \%$.

No chromosome abnormalities were missed and, in the $40+$ age group, 11 abnormalities were detected in 243 pregnancies $(4.5 \%)$, whereas in the 35 to 39 age group, three abnormalities were detected in 125 pregnancies $(2.4 \%)$.

Of the 16 pregnancies with neural tube defects, ten were referred because of a previous NTD, giving a detection rate of $10 / 362(2 \cdot 8 \%)$.

Very few cases were encountered in which there was no apparent clinical reason for amniocentesis (table 3). The case in which the indication given was a threatened abortion in the present pregnancy did in fact result in a spontaneous abortion four days after the amniocentesis.

Although there were 38 terminations, 31 were as a consequence of a detected abnormality and four were of male fetuses with a high risk of carrying disease. Of the remaining three, one woman had a large ovarian cyst, one apparently normal pregnancy was terminated after the finding of a 46,XX, 22p+ karyotype (this woman has subsequently had a perfectly normal pregnancy), and one woman had a private social termination of her pregnancy. Her indication for amniocentesis was for her age of 39 years.

Two of the balanced translocations were de novo, and one set of parents elected for a termination.

Both pregnancies with mosaic chromosome results were allowed to continue with the birth of two normal female babies. The extra number 2 chromosome was present in only one colony, while a repeat amniocentesis of the apparent Turner's syndrome pregnancy yielded a sample with only $46, \mathrm{XX}$ cells. The pregnancy ended with the birth of a normal female infant, exactly as has been reported in a previous case. ${ }^{3}$

Altogether $918 / 1000$ pregnancies resulted in a live baby $(91.8 \%)$. No chromosome result was obtained in 154 of these. Of the 43 spontaneous fetal losses, 13 had a chromosome failure. So of 154 failures, 13 fetuses were spontaneously lost $(8.4 \%)$. This is

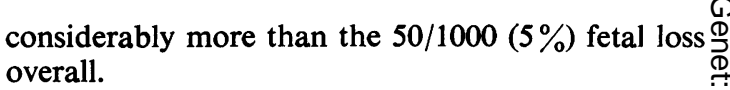

There were seven errors in predicting the sex of $\Rightarrow$ the fetus, all from one laboratory (BMH). Four $\stackrel{5}{+}$ were diagnosed as $46, \mathrm{XX}$ and a male was born, and $\mathrm{O}$ three had the less likely combination of a $46, X Y$ 음 chromosome result being followed by the birth of $\mathrm{a} \stackrel{\mathrm{D}}{\vec{D}}$ female infant.

Throughout this study, the age of the mothers to whom amniocentesis was offered because of the $\vec{O}$ increased risk of Down's syndrome was 38 years, although younger women were accepted at the dis- $\vec{\omega}$ cretion of the obstetricians. During 1976, however, only 4.6 pregnancies in 1000 livebirths were tested, whereas in other regions up to 32.6 pregnancies in 1000 livebirths received amniocentesis. ${ }^{4}$ A survey within the region has shown that patients at certain $\infty$ centres are at an advantage even within the West Midlands Region itself.

In an attempt to estimate the risks in the procedure, $\vec{\nabla}$ the numbers of fetal losses after amniocentesis were음 compared with those suffered by all patients in one large hospital (BMH). Although this is not a true $\overrightarrow{0}$ control group, only fetal loss after 16 weeks of ${ }^{\infty}$ gestation was considered, and the group was divided into mothers above and below the age of? 35 to eliminate the age bias inherent in the subjects. Amniocentesis carried a risk of 1 to $1.5 \%$ to the fetus, which is in agreement with other findings. ${ }^{5}$

We would like to thank Action Research for the $\overrightarrow{\vec{O}}$ Crippled Child and the West Midlands Regional Health Authority for supporting this work.

\section{References}

1 Canadian Medical Research Council. Diagnosis of genetic disease by amniocentesis during the second tri-ㄱ. mester of pregnancy. Can MRC Rep 1977; No 5.

2 Galjaard H. European experience with prenatal diagnosis

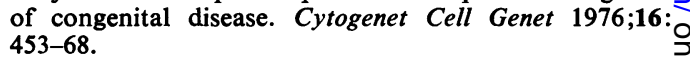

3 Polani PE, Alberman E, Alexander BJ, et al. Sixteen $D$ years' experience of counselling, diagnosis, and prenatalo detection in one Genetic Centre: progress, results, and problems. J Med Genet 1979;16:166-75.

4 Clinical Genetics Society Working Party on Prenatar Diagnosis in Relation to Genetic Counselling. The $\mathcal{O}$ provision of services for the prenatal diagnosis of fetalN abnormality in the United Kingdom. Bull Eug Soc
1978;No3.

5 Medical Research Council. Working party on amnioso centesis report: an assessment of the hazards of amnio- $\bar{\Phi}$ centesis. Br J Obstet Gynaecol 1978;85 :suppl 2.

Requests for reprints to Dr Tessa Webb, Depart-ō ment of Clinical Genetics, Birmingham Maternity喵 Hospital, Birmingham B15 2TG. 